ZHIJIE YANG, Graduate Research Assistant ${ }^{1}$

E-mail: yangzhijie@live.com

XIAOLONG CHEN, Ph.D. ${ }^{1}$

E-mail: chenxl@tongji.edu.cn

1 Tongji University

Shanghai Siping Road No.1239, China
Traffic Planning

Original Scientific Paper

Submitted: 24 Apr. 2018

Accepted: 4 Apr. 2019

\title{
COMPENSATION DECISIONS ON DISRUPTION RECOVERY SERVICE IN URBAN RAIL TRANSIT
}

\begin{abstract}
Ride-hailing, in addition to a common mode of daily transportation, is an attractive option for evacuating stranded passengers and supplementing bus bridging in the early stages of an urban rail transit (URT) disruption. This paper proposes a service supply chain comprised of ride-hailing vehicles, ride-hailing platforms, and stranded passengers wherein the URT and ride-hailing chain together provide emergency evacuation services. The emergency evacuation service supply chain can be coordinated under an effort-based revenue sharing contract. A URT-dominated Stackelberg game model between the URT and ride-hailing platform is then formulated to optimize compensation decisions on the part of the URT; numerical analysis reveals critical factors affecting the said decisions. The main contributions of this paper are two-fold: first, it provides new information regarding collaboration between URT operators and ride-hailing platforms for stranded passenger evacuation, in cluding a ride-hailing platform pricing strategy; and second, the URT compensation decision process is solved via Stackelberg game model while revealing an incentive coefficient parameter for the URT decision and solver.
\end{abstract}

\section{KEY WORDS}

urban rail transit; disruption recovery; effort-based revenue sharing contract; compensation decisions;

\section{INTRODUCTION}

Urban rail transit (URT) systems are vital channels for commuters and provide necessary support for a wide array of mobility demands in metropolitan areas. However, URT systems are prone to disruptions caused by network failures, outbursts of passenger flows, natural disasters, and terrorist activities. Timely and effective management procedures are crucial to mitigate the societal impact of URT disruptions; it is necessary to ensure effective temporary operation for unaffected sections as well as recovery services for evacuating stranded passengers from the affected stations.

Ride-hailing services have rapidly increased in popularity and availability in recent years. There were 410,000 registered ride-hailing vehicle drivers in Shanghai in 2016. Theoretically, an equivalent number of vehicles can potentially be used to provide recovery services in the case of a URT disruption. Ride-hailing services are cheaper than taxis. If the URT provides certain compensation in addition, more stranded passengers would theoretically be able to transfer to ride-hailing vehicles to complete their commute - to this effect, ride-hailing may complement bus-bridging for disruption recovery. More importantly, ride-hailing vehicles can provide point-to-point service rather than feeder service, which is an attractive option for passengers on stricter timelines. The URT may benefit from cooperating with ride-hailing companies to provide recovery services to evacuate stranded passengers in the case of a disruption.

This paper focuses on collaboration between a URT and ride-hailing company for recovery service during railway disruption events. Ride-hailing is explored as potential compensation for disrupted URT services, the expected profits of participants are analysed, and a corresponding URT decision-making technique is established.

\section{LITERATURE REVIEW}

URT disruption recovery is designed to mitigate the effects of a service disruption and recover to the original operation state. Disruption management is defined by Jespersen-Groth et al. as the "joint approach of the involved organizations to deal with the impact of disruptions in order to ensure the best possible service for the passengers" [1]. Bus-bridging is the most common response to rail service disruption as identified in an international survey of rail authorities [2]. The extant research on bus-bridging centres on operational issues in terms of route design [3], bridging termini locations [4], or reserve bus depot locations [5]. Bus-bridging passengers are subjected to at least two passive transfers (URT-Bus-URT), which is burdensome, time-consuming, and representative of a significant decline in service satisfaction. Feeder stations in the case of bus-bridging may also be overwhelmed by the sudden increase in passenger flow as evacuated individuals are re-routed through them. 
Many previous researchers have explored URT disruption recovery. Westerlund Y. et al. [6], for example, investigated efforts by public transport systems in Sweden and the Netherlands in collaboration with taxi companies to provide demand-responsive transport services. Darmanin et al. [7] examined the consequences of disruptions on the Melbourne Metro Train. They established a mathematical model with minimal commuter "discomfort" under a number of operational constraints. Their model proved able to transport more stranded commuters to their designated destinations at any point in time as compared to the current strategy.

There have been many other valuable contributions to the literature in terms of URT policy. Schuitema et al. [8] found that transport pricing acceptability is not necessarily low because URT users expect negative effects in terms of usage of personal vehicles, but rather because they are not convinced that public transport policies reduce traffic congestion or environmental problems. Zeng et al. [9] explored the effects of taxi-based recovery services on short-term disruptions in public tram systems, as well as the financial effects thereof. The pricing strategy can be a useful tool in coordinating various modes of transportation in terms of supply chain management [10], inventory management [10], and emergency traffic problems [8].

No previous researcher has proposed a direct application of a cooperative URT disruption recovery plan. Cooperation with ride-hailing companies is, in effect, a decision-making problem for the URT. How does the URT decide whether to cooperate with ride-hailing services? How much do they compensate for recovery services, and how do they encourage partners to provide the required services on short notice? The objective of the present study was to establish models that may be used to guide URT/ride-hailing recovery service compensation.

\section{DELAY MODEL APPROACH}

\subsection{Incident area}

Here, an "incident area" is defined as a set of stations in the line forced to stop the operation due to a disruption in any individual station. In short, the incident area is comprised of the stations between two nearby crossovers. When a station suffers disruption, the line can only use the crossovers for temporary operation until system recovery. Crossovers act as temporary turning lines to ensure the temporary operations of other sections. The disruption can suspend not only the station itself but also any stations nearby without any crossover. A line can be divided into a number of consecutive incident areas according to the crossovers; the incident area is defined by the topological characteristics [11].

The space-L method was used to draw URT lines based on complex network theory. Stations can be virtualized into nodes of complex networks, while sections can be virtualized into links which connect the nodes. The URT line can be represented by an undirected graph $L(V, E)$. The node set $V=\left\{v_{i} \mid i=1,2, \ldots n\right\}$ represents successive stations and the link set $E=\left\{e_{i} \mid i=0,1, \ldots n\right\}$ represents successive sections. The set of links equipped with crossovers is denoted as $E^{\prime}\left(E^{\prime} \subseteq E\right)$ and the number of crossovers is denoted as $n\left(E^{\prime}\right)$. If $e_{k^{\prime}}, e_{m} \in E^{\prime}$ and $e_{k^{\prime}}, e_{m}$ are adjacent links, the incident area can be defined by an undirected graph $I A_{m}\left(V^{\prime}, E^{\prime}\right)$. A line can be separated into $n\left(E^{\prime}\right)-1$ consecutive incident areas according to the crossovers.

$$
\left\{\begin{array}{l}
V^{\prime}=\left\{v_{i} \mid i=k+1, k+2, \ldots, m\right\} \\
E^{\prime}=\left\{e_{i} \mid i=k, k+2, \ldots, m\right\}
\end{array}\right.
$$

\subsection{Disruption delay model}

The bathtub model is used to study the disruptions; Figure 1 shows the disruption and the recovery process. The system state is denoted as $S$ on y-axis, the time is

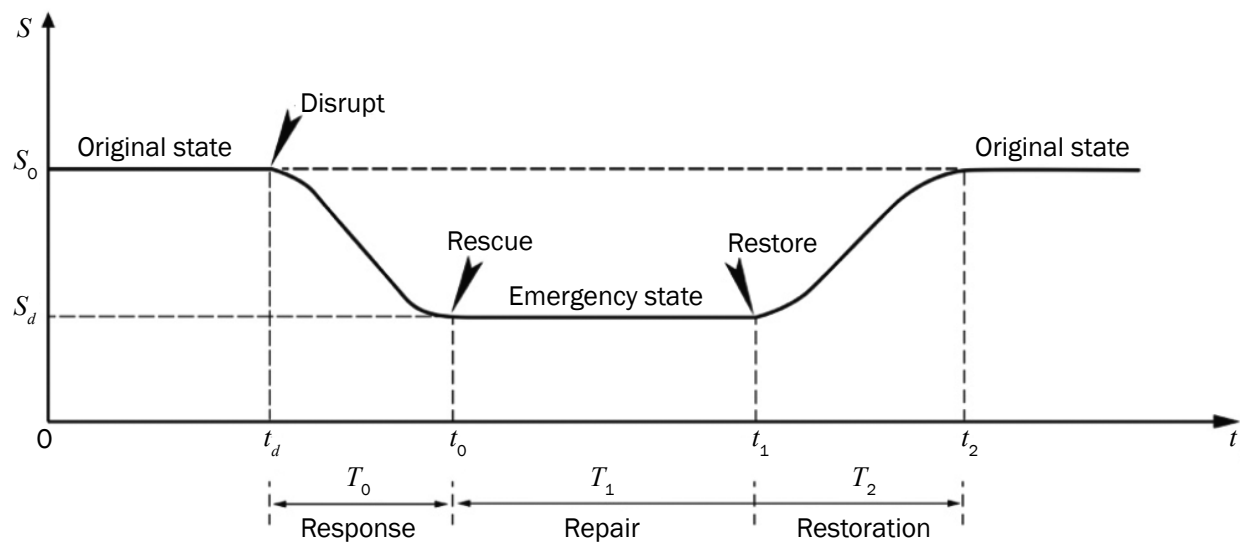

Figure 1 - URT disruption and recovery process 
denoted as $t$ on x-axis. When an incident disrupts a station at time $t_{d}$, an incident area is formulated. It is assumed that the URT supervisor judges and enacts rescue measurements at time $t_{0}$ and that waiting passengers gather and the system state declines from the original state to the emergency state $S_{d}$; the duration is denoted as $T_{0}$, the traffic and service level remain at a lower level during the emergency state. "Rescue measurements" include the removal of dangerous elements, temporary operation, and stranded passengers evacuation. The disruption ends and the incident stations are restored at time $t_{1}$; the duration is denoted as $T_{1}$. The system state is restored from emergency state $S_{d}$ to original state $S_{0}$ at time $t_{2}$, at which point there are no more stranded passengers in the system. Rescue measurements are completed before $t_{2}$; the duration is denoted as $T_{2}$.

$T_{m}$ is used to denote the recovery service duration. When the incident stations restore the operation, if the number of passengers stranded in the stations is small and the stranded passengers can board the first arriving train, the delay caused by the disruption has ended. If the stranded passengers remain on the platform after the restoration and the capacity of the first arriving train is insufficient, the delay continues. Two delay models have been designed accordingly: Delay Model 1 (delay ends after restoration), and Delay Model 2 (delay continues after restoration) [12].

\section{Delay Model 1}

When the incident station operation is restored, if the stranded passengers volume is smaller than the remaining capacity of the train $\left(Q_{1} \leq Q_{c}\right)$, then passengers waiting at the platform can freely board the first arriving train. Any passengers arriving subsequently are not affected by the disruption. The delay duration is denoted as $T_{m}=T_{0}+T_{1}$. The impacted passengers include those in the system at the time of the disruption and those who arrived and waited on the platform within the delay duration. The accumulative passengers are denoted as:

$$
Q=\sum_{i=1}^{n}\left(Q_{i 0}+\Delta \psi_{i} T_{m}\right)
$$

where $Q_{i 0}$ denotes the passengers waiting at station $i$ (who can be counted according to SIM-card data). Passengers behave differently depending on the nature and extent of the disruptive incident. They may continue to wait at station $i$ for restoration to reach their destination, or they may become impatient and leave station $i$ [13]. The stranded passenger growth rate is denoted as $\Delta \psi_{i}=\psi_{i a}-\psi_{i u} ; \psi_{i a}$ denotes the passenger arrival rate at station $i$ and $\psi_{i u}$ denotes the rate at which the impatient passengers leave the station.

The total delay caused by the disruption is determined by the delay of the original passengers and the stranded passengers growth rate during the delay duration, which is represented by the shaded area in Figure 2. The total delay of stranded passengers is calculated via Equation 3.

$$
T=\sum_{i=1}^{n}\left(Q_{i 0} T_{m}+\frac{1}{2} \Delta \psi_{i} T_{m}^{2}\right)
$$

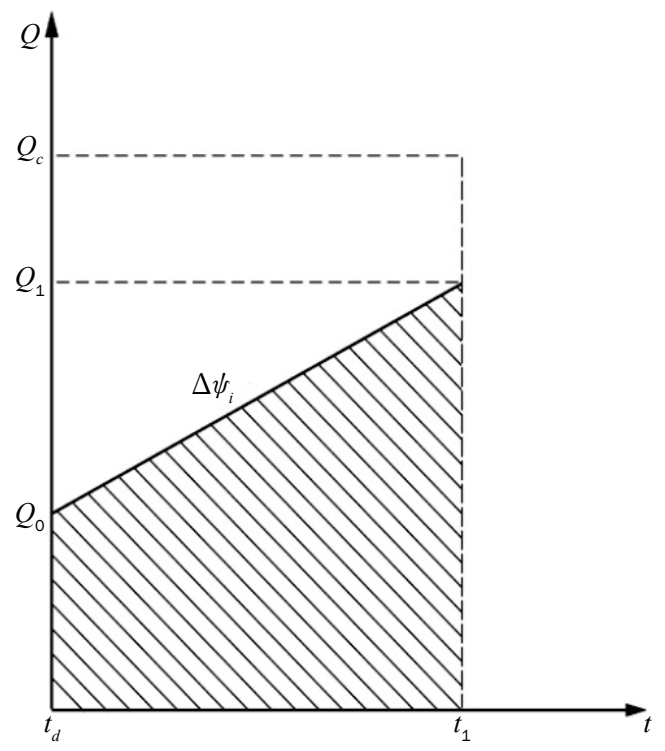

Figure 2 - Accumulated passenger change in Delay Model 1

\section{Delay Model 2}

When the incident stations resume operation, if $Q_{1}>Q_{c}$, the line enters a temporary full-load operation state. The delay duration continues until no stranded passengers are waiting on the platform and passengers continue to wait without leaving the station. The delay duration is denoted as $T_{m}=T_{0}+T_{1}+T_{2}$. The impacted passengers include the portion who have been in the system since the disruption began and the portion who have arrived at the platform within the delay time. The accumulative passengers are denoted as:

$Q=\sum_{i=1}^{n}\left(Q_{i 0}+\Delta \psi_{i}\left(T_{0}+T_{1}\right)+\psi_{i a} T_{2}\right)$

where $Q_{i 0}$ denotes the passengers waiting at station $i$ uploaded from the trains out of service plus the passengers waiting at station $i$ at time $T_{0}$. The passenger volume growth rate is denoted as $\Delta \psi_{i}$; the passenger arrival rate is denoted as $\psi_{a i}$.

During the passenger evacuation phase, it is assumed that there are no impatient passengers leaving the station and that stranded passengers queue to board the next train. The passenger departure rate is higher than the passenger arrival rate. The stranded passengers volume declines at a rate of $\psi_{i d}-\psi_{i a}$. The total delay caused by the disruption is the shaded area in Figure 3 calculated via Equation 5.

$T=\sum_{i=1}^{n}\left(Q_{i 0} T_{1}+\frac{1}{2} \Delta \psi_{i}\left(T_{0}+T_{1}\right)^{2}+\frac{\left(Q_{i 1}-Q_{i c}\right)^{2}}{2\left(\psi_{i a}-\psi_{i l}\right)}\right)$ 


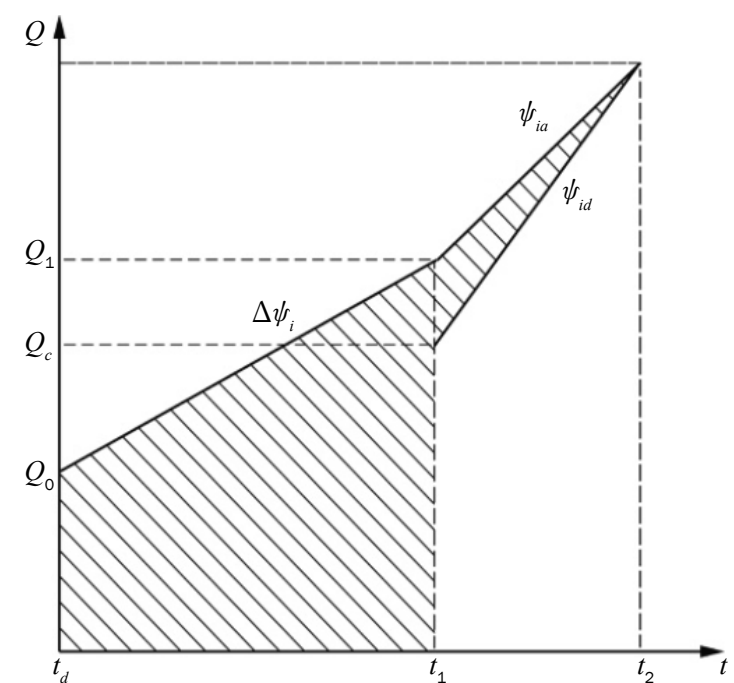

Figure 3 - Accumulated passenger change in Delay Model 2

\subsection{Average delay loss estimation}

The societal loss caused by delays in a URT disruption is mainly reflected in the time-value loss of passengers who endure a lengthier than normal commute. The time value is also reflected in the value of an hourly labour force. The average time value is denoted as $h$ and the average loss is defined as follows:

$c_{l}=\frac{T h}{Q}$

\section{RECOVERY SERVICE COMPENSATION APPROACH}

Our analysis is centred here on a scenario in which a URT company collaborates with a ride-hailing company to manage short-term disruptions (e.g., duration of less than two hours). An X company is used as the research subject, which is a platform covering taxis and personal ride-hailing vehicles. The recovery service is a transport supply consisting of ride-hailing vehicles, $X$, and stranded passengers as participants.

We first analysed the revenue-sharing contract between $X$ and the vehicles due to the large demand caused by the disruption. $X$ provides immediate services for a large number of stranded passengers, and transfers a portion of its revenue to encourage more potential vehicles to evacuate the stranded passengers. $X$ must strike a trade-off between the transfer of revenue to other vehicles and the quantity of passengers transferred. The disruptions vary in occurrence time, duration, and the number of passengers stranded; under certain disruption scenarios. The URT may not benefit from the compensatory recovery services. The URT must also trade-off its recovery costs and passenger services. These factors were taken into account in designing a model for URT recovery compensation decision-making.

\subsection{Notations and assumptions}

Our modelling process was conducted using the following notations and assumptions.

1) It is assumed that the stranded passengers wait for URT operation restoration. If there is no recovery service provided, the societal loss may be denoted as the time value cost. If the URT collaborates with $X$ to provide recovery service, some stranded passengers may transfer to ride-hailing vehicles for their remaining commute, which saves inestimable delays. URT pays compensation to $\mathrm{X}$ for the recovery service via the interrelation shown in Figure 4.

2) Aggregate passenger behaviour is considered rather than individual reactions during a disruption. During the delay, the volume of aggregate passengers willing to transfer to ride-hailing vehicles are assumed to decrease as X's service price $(p)$ increases and the vehicle effort degree $(e)$ decreases. If vehicles arrive in about the same amount of time as the duration of the disruption, then only a small portion of passengers $\left(\lambda_{0}-\lambda_{1} p\right)$ will use a ride-hailing vehicle. The transfer passenger volume is assumed to be a linear function of the average payment and vehicle effort degree ([9]), the maximum of which must fall below the accumulative passengers of the incident area as $Q(p, e)<Q$.

$Q(p, e)=\left(\lambda_{0}-\lambda_{1} \frac{p}{p_{0}}+\lambda_{2} \frac{e}{e_{0}}\right) Q$

where $Q(p, e)$ denotes the stranded passengers transfer to ride-hailing vehicles, $p$ is the unit price of ride-hailing, $e$ is the effort expended by the ride-hailing vehicles, $p_{0}$ is the minimum unit price of ride-hailing, $e_{0}$ is the minimal effort expended by the ride-hailing vehicles, $\lambda_{0}, \lambda_{1}, \lambda_{2}$ are positive coefficients to be calibrated, and $Q^{\prime}$ denotes the

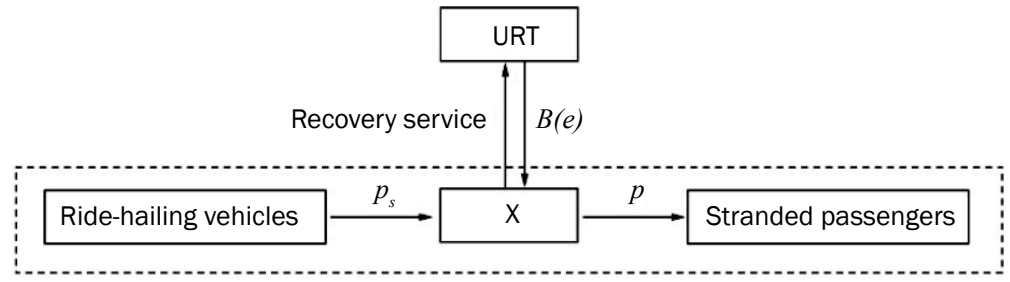

Figure 4 - Cooperation among recovery service participants 
stranded passenger volume of the incident area its maximum is less than the accumulative passengers of the incident area, as $Q(p, e)<Q$.

3) Under normal circumstances, ride-hailing vehicles provide nearby services and do not input any extra effort. In a recovery scenario, $\mathrm{X}$ must convene more ride-hailing vehicles, some of which must reach the incident area from a distance and thus merit special incentive to participate in the recovery (defined here as "effort"). It is reasonable that the cost of effort $G(e)$ be a convex function of the degree of effort. The normal cost and marginal cost both increase as effort degree increases, as $G^{\prime}(e)>0$, $G^{\prime \prime}(e)>0$.

$G(e)=\frac{1}{2} \delta e^{2} Q(p, e)(\delta>0)$

where $G(e)$ denotes the cost of ride-hailing vehicles, $\delta$ is a positive coefficient to be calibrated, $e$ is the effort made by the ride-hailing vehicles (greater effort paid indicates more vehicles participating in the emergency evacuation with shorter response time), and $Q^{\prime}$ denotes the stranded passenger volume of the incident area.

4) The URT is inclined to provide compensation for recovery services in order to evacuate as many stranded passengers as possible. In doing so, they may benefit from incorporating ride-hailing vehicles into the recovery service. The compensation is assumed as an affine function of effort degree, $b_{h}$ is the maximum compensation, $\beta$ is the compensation coefficient, and $e_{0}$ is the minimum effort degree required.

$$
B(e)=b Q=\beta e Q(p, e)\left(e \geq e_{0}, \beta>0, \beta e<b_{h}\right)
$$

where $\beta$ is a positive evacuation coefficient to be calibrated, $e$ is the effort made by the ride-hailing vehicles, $Q^{\prime}$ is the stranded passenger volume of the incident area, $e_{0}$ is the minimal effort made by the ride-hailing vehicles, and $b_{h}$ is the maximum evacuation cost.

\subsection{Recovery service supply chain analysis}

Under recovery circumstances, $\mathrm{X}$ provides recovery services by conveying passengers to their destinations rather than feeder services of conveying passengers to the nearest URT stations. Recovery service supply chain participants include ride-hailing vehicles, $X$, and stranded passengers. $X$ provides the service platform for the ride-hailing vehicles and passengers. Stranded passengers purchase transport service to $\mathrm{X}$; $\mathrm{X}$ deducts service fees, information fees, and other fees before transferring the remaining payment to ride-hailing vehicles.
$X$ 's expectation is to maximize its profit. Revenue mainly includes passenger payments and URT compensation. Expenditures mainly include the transfer payment to ride-hailing vehicles and operation costs.

$\Pi_{r}(p, e)=\left(p-p_{s}-c_{r}\right) Q(p, e)+B(e)$

The ride-hailing vehicle company's expectation is also to maximize its profit. Revenue mainly includes the transfer payment from $X$ and expenditures mainly include operation and effort costs.

$\Pi_{s}(p, e)=\left(p_{s}-c_{s}-c_{r}\right) Q(p, e)-G(e)$

The purpose of supply chain management is to maximize overall profit. In a state of centralized decision-making, $X$ and ride-hailing vehicles are considered as a whole. The pricing strategy and effort strategy reach a global optimum. The expected profit function of the service supply chain is expressed as follows:

$\Pi(p, e)=\Pi_{s}+\Pi_{r}=\left(p-c_{s}-c_{r}\right) Q(p, e)+B(e)-G(e)$

The optimal pricing and effort degree meet the following first-order conditions:

$$
\begin{aligned}
& \frac{\partial \Pi\left(p^{*}, e\right)}{\partial p}=\left(p^{*}-c_{s}-c_{r}\right) \frac{\partial Q\left(p^{*}, e\right)}{\partial p}+Q\left(p^{*}, e\right)=0 \\
& \frac{\partial \Pi\left(p, e^{*}\right)}{\partial e}=\left(p-c_{s}-c_{r}\right) \frac{\partial Q\left(p, e^{*}\right)}{\partial e}+B^{\prime}\left(e^{*}\right)-G^{\prime}\left(e^{*}\right)=0
\end{aligned}
$$

Each supply chain member is assumed to be rational, the individual decision-making serves to maximize respective profits, and a decrease in overall profit is inevitable.

\subsection{Effort-based revenue-sharing contract}

The revenue-sharing contract is the basic measurement of supply chain coordination [14]. Under the traditional revenue-sharing contract, ride-hailing vehicles offer transport services on $\mathrm{X}$ platform. $\mathrm{X}$ dominates the supply chain and transfers a part of the service revenue and compensation to the ride-hailing vehicles under Proposition 1.

Proposition 1: The traditional revenue-sharing contract cannot be coordinated.

Proof:

$X$ 's expected profit function is

$$
\Pi_{r}(p, e)=\left(\varphi p-p_{s}-c_{r}\right) Q(p, e)+\varphi B(e)
$$

The optimal price meets first-order conditions as follows:

$$
\begin{aligned}
& \frac{\partial \Pi_{r}\left(p_{\varphi, e}^{*}\right)}{\partial p}= \\
& \left(\varphi p_{\varphi}^{*}-p_{s}-c_{r}\right) \frac{\partial Q\left(p_{\varphi}^{*}, e\right)}{\partial p}+\varphi Q\left(p_{\varphi}^{*}, e\right)=0
\end{aligned}
$$


The optimal price $p_{\varphi}^{*}$ must be equal to $p^{*}$ to reach supply chain coordination. The optimal transfer payment can be obtained, $p_{s}=\varphi c_{s}+(\varphi-1) c_{r}$, and the ride-hailing vehicles' expected revenue can be further calculated as follows:

$$
\Pi_{s}(p, e)=(1-\varphi)\left(p-c_{s}-c_{r}\right) Q(p, e)-G(e)
$$

The optimal effort degree meets the following first-order conditions:

$$
\begin{aligned}
& \frac{\partial \Pi_{s}\left(p, e_{\varphi}^{*}\right)}{\partial e}= \\
& (1-\varphi)\left(p-c_{s}-c_{r}\right) \frac{\partial Q\left(p, e_{\varphi}^{*}\right)}{\partial e}-G^{\prime}\left(e_{\varphi}^{*}\right)=0
\end{aligned}
$$

Because $\varphi>0, B^{\prime}\left(e^{*}\right)>0$, then $e_{\varphi}^{*}(p)<e^{*}(p)$. Supply chain coordination cannot be achieved. It is reasonable that the ride-hailing vehicles bear an overall effort cost $G(e)$, but receive only a partial payment $(1-\varphi)\left(p-c_{s}-c_{r}\right) Q(p, e)$. Thus, the effort degree made by the vehicles is lower than the supply chain's optimal effort degree.

We propose a revenue-sharing contract model based on effort cost-sharing, where $X$ company shares the effort cost at a rate denoted as $\mu$.

Proposition 2: If $\varphi$ and $p_{s}$ satisfy Equation 20, the effort-based revenue-sharing contract reaches the appropriate degree of coordination.

$\left\{\begin{array}{l}\varphi=\mu \\ p_{s}=\varphi c_{s}+(\varphi-1) c_{r}\end{array}\right.$

Proof:

If $\varphi=\mu, p_{s}=\varphi c_{s}+(\varphi-1) c_{r}$, X's expected profit function is:

$$
\begin{aligned}
& \Pi_{r}\left(p^{*}, e^{*}\right)=\left(\varphi p^{*}-p_{s}-c_{r}\right) Q\left(p^{*}, e^{*}\right)+\varphi B\left(e^{*}\right)-\mu G\left(e^{*}\right) \\
& =\left(\varphi p^{*}-\varphi c_{s}+(\varphi-1) c_{r}-c_{r}\right) Q\left(p^{*}, e^{*}\right)+\varphi B\left(e^{*}\right)-\varphi G\left(e^{*}\right) \\
& =\varphi\left(p^{*}-c_{s}-c_{r}\right) Q\left(p^{*}, e^{*}\right)+\varphi B\left(e^{*}\right)-\varphi G\left(e^{*}\right) \\
& =\varphi \Pi\left(p^{*}, e^{*}\right)
\end{aligned}
$$

X's expected profit function is an affine function of the service supply chain's profit function. The revenue-sharing contract is thus coordinated. The value of $\varphi$ is mainly determined by negotiation between $X$ and the ride-hailing vehicles, and the optimal pricing strategy is reflected in Equation 12.

\subsection{Recovery service compensation model}

The URT seeks maximum evacuation effects with minimum compensation. The expected profit is the reduction of societal loss.

$$
\begin{aligned}
& O=Q_{0} c_{l}-\left(\left(Q_{0}-Q(p, e)\right)_{l}+Q(p, e) p+B(e)\right) \\
& =Q(p, e)\left(c_{l}-p\right)-B(e)
\end{aligned}
$$

During the recovery service, $X$ works under the participation constraint that URT makes the minimum effort $\left(e \geq e_{0}\right)$ while attempting to maximize the profit function with optimal effort. The game between URT and $\mathrm{X}$ is formulated here as a URT-dominated Stackelberg game model which can be solved by the backward induction method [15].

Step 1: Affording price $p$, the optimal effort degree meets the first-order conditions of X's expected profit function.

$$
\begin{aligned}
& \frac{\partial \Pi_{r}\left(p, e^{*}\right)}{\partial e^{*}}= \\
& \varphi\left(p-c_{s}-c_{r}\right) \frac{\partial Q\left(p, e^{*}\right)}{\partial e^{*}}+\varphi B^{\prime}\left(e^{*}\right)-\varphi G^{\prime}\left(e^{*}\right)=0 \\
& e^{*}=\frac{\lambda_{2}\left(p-c_{s}-c_{r}\right)+\beta e_{0}}{\delta e_{0}}
\end{aligned}
$$

Step 2: Bringing $e^{*}$ into the URT expected profit function makes the optimal compensation incentive coefficient $\beta^{*}$ meet the first-order conditions of the URT expected profit function.

$$
\frac{\partial O\left(p, e^{*}, \beta^{*}\right)}{\partial \beta^{*}}=\frac{\partial Q\left(p, e^{*}, \beta^{*}\right)}{\partial \beta^{*}}\left(c_{l}-p\right)-\frac{\partial B\left(e^{*}, \beta^{*}\right)}{\partial \beta^{*}}=0
$$

When X's pricing strategy is known in advance, the compensation incentive coefficient is:

$\beta^{*}=\frac{\lambda_{2}\left(c_{l}-2 p+c_{s}+c_{r}\right)}{2 e_{0}}$

\section{NUMERICAL ANALYSIS}

\subsection{Illustrations}

A few numerical examples have been assessed to explore the URT company's reduced loss and the $X$ company's profit under various impact parameters. Shanghai URT network and company $X$ were chosen as subjects. A computer was used with $2.6 \mathrm{GHz}$ dual-core CPU for computation. The input variables and parameters for the model can be sorted into four groups.

1) Variables related to the URT disruption include the four stations between the Tongji university station and Jiangwan stadium station (Line 10) as one incident area; these four stations were selected as our analysis subject. The disruption occurs at 11:00, the recovery service approaches at 11:30, then the four stations are restored at 13:00, and the stations resume original operation at 13:30.

2) Variables related to the passengers (e.g., arrival and departure rates) were obtained from workday operation data in October of 2016. The mean arrival rate of the study area was 721 passengers per station per hour and the mean departure rate was 731 passengers per station per hour between 11:00 and 14:00. The number of initial stranded passengers at each station was assumed to be 450. "Impatient" passengers were assumed to leave the station at a rate in direct proportion to the passenger arrival rate, $\psi_{i u}=0.3 \psi_{i a}$. Delay Model 2 was used to calculate the stranded passenger volume. The average time value of the passengers 
was calculated as per the average salary of the city (37 yuan/hour in 2016). The average commute distance of URT passengers was obtained from an annual traffic survey report as 15.8 kilometres in 2016.

3) Variables related to $X$ involve the service price (comprised of distance price and duration price). The distance unit price changes from 0.6 to 2 per kilometre; the duration unit price is assumed to be 0.4 per minute, and the values can be adjusted according to actual data. The minimum charge was 11 yuan/person as of 2016. The travel speed of ground transportation changes from 15 to 40 as congestion varies - the mean value was 30 kilometres per hour in Shanghai in 2016. The travel speed affects the recovery service duration when travel distance is constant.

4) Due to unavailable data, we simply assumed some parameters to be constant values for passenger loss estimation (Table 1).

\section{2 "With or without" comparison}

Under the given assumptions, the accumulative passenger volume (Equation 4) and average loss (Equation 6) were first calculated based on Delay Model 2. The optimal compensation incentive coefficients (Equation 24) were then calculated according to different service prices to obtain the optimal effort degree (Equation 23) and accumulative passengers (Equation 7). The URT expected profit (Equation 21) was calculated last. The results without any recovery service were also obtained for comparison as plotted in Figure 5.

It was found that transfer passenger volume decreases monotonically as service price increases in Models 1 and 2 . The transfer passenger volume with recovery service fell below the volume without recovery service when the price was 22.91; the URT refuses to collaborate with $\mathrm{X}$ if the price reaches this value. It was also found that volumes increase as prices decrease more significantly with recovery service than without recovery service; the volume difference is particularly significant when service price is low. It is worthwhile to promote recovery services for stranded passenger evacuation under disruption. The transfer rate and profit of both companies increase as the service prices decrease. In other words, it is profitable for $X$ to collaborate with the URT for the recovery service provision and relatively low service prices are worth offering to passengers.

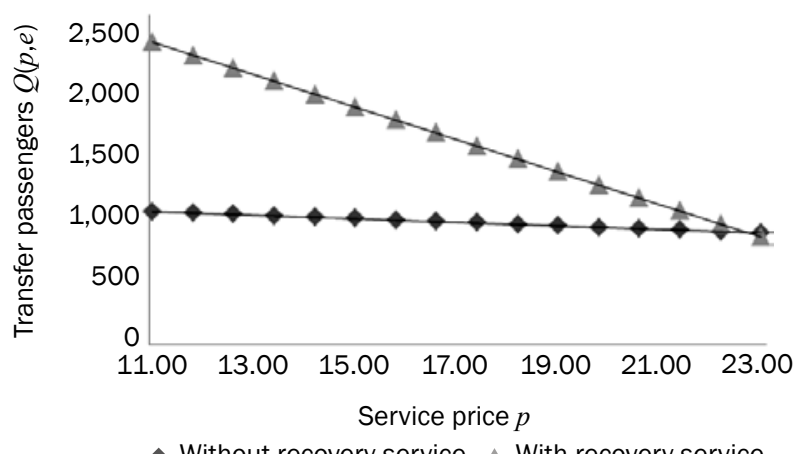

- Without recovery service $\Delta$ With recovery service

Figure $5-Q(p, e)$ changes with different $p^{*}$ ("with or without")

\subsection{Sensitivity analysis}

Case 1: Individual impact of service price

According to the X's lowest service price constraint and URT's compensation constraint, the service price is restricted between 11 and 23. The recovery compensation (Equation 9) and $\mathrm{X}$ marginal expected profit (Equation 15) was calculated as shown in Figure 6a. We further calculated the URT expected profit (Equation 21) as shown in Figure $6 b$. The recovery compensation and

Table 1 - Input parameter values (Numerical example)

\begin{tabular}{||l|c|c||}
\hline \multicolumn{1}{|c|}{ Parameter } & Notation & \multicolumn{1}{c|}{ Value } \\
\hline \hline Response time & $T_{0}$ & $T_{1}$ \\
\hline Repair time & $T_{2}$ & $1.5 \mathrm{~h}$ \\
\hline Restoration time & $\lambda_{0}$ & $0.5 \mathrm{~h}$ \\
\hline Basic transfer coefficient & $\lambda_{1}$ & 0.2 \\
\hline Price impact coefficient & $\lambda_{2}$ & 0.01 \\
\hline Effort impact coefficient & $\delta$ & 0.2 \\
\hline Effort cost parameter & $c_{r}$ & 5 \\
\hline X operation cost per person & $c_{s}$ & 1 yuan \\
\hline Ride-hailing vehicle operation cost per person & $\varphi$ & 3 yuan \\
\hline X sharing proportion of revenue sharing contact & $e_{0}$ & 0.2 \\
\hline Minimal effort degree & $b_{h}$ & 0.5 \\
\hline Maximum compensation per person & & 5 yuan \\
\hline Average passengers per vehicle & & 2.5 persons/vehicle \\
\hline
\end{tabular}


URT's expected profit both decrease as price increases; X's expected profit reaches its maximum at the price of 13.43, as shown in Figure $6 a$.

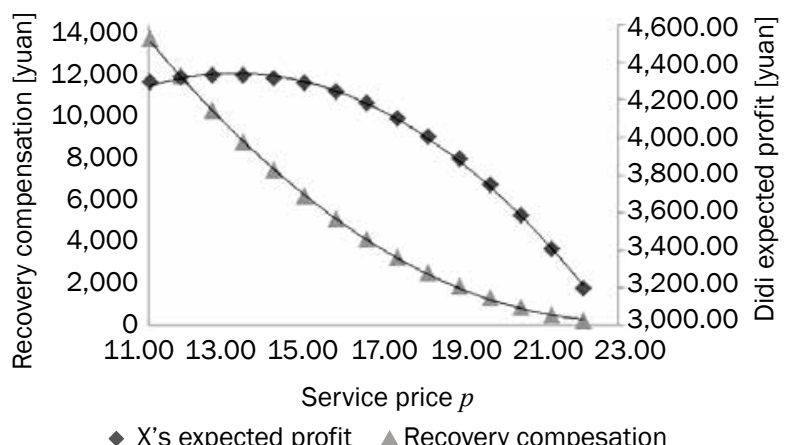

Figure $6 a-B(e)$ and $\Pi_{r}(p, e)$ changes with different service price

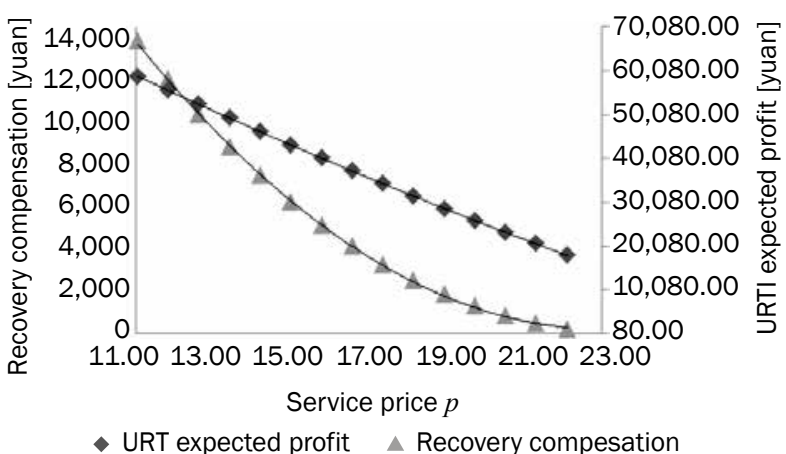

Figure $6 b-B(e)$ and 0 changes with different service price

The effort cost (Equation 8) and service supply chain expected profit (Equation 12) were calculated as shown in Figure 7. Generally speaking, ride-hailing vehicles pay less effort when prices are low. The URT could pay greater compensation for recovery services when prices decline to encourage ride-hailing vehicles to expend greater effort. The service supply chain expected profit reaches its maximum at unit compensation of 4.10 (Figure 7).

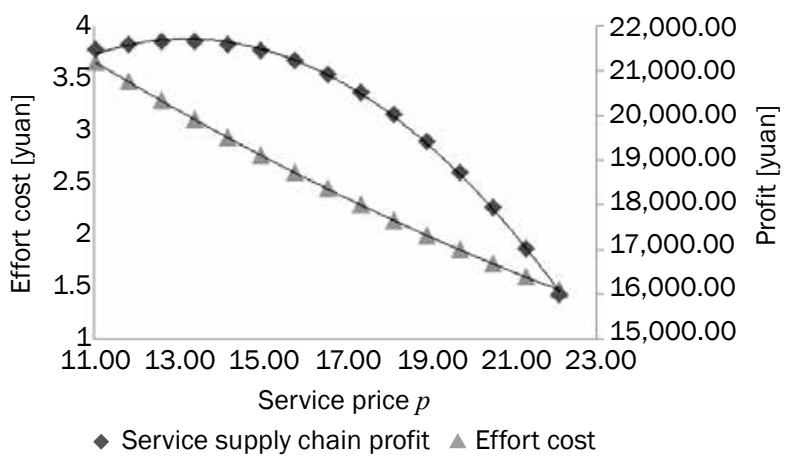

Figure $7-G(e)$ and $\Pi(p, e)$ changes with different service price
Case 2: Individual impact of vehicle travel speed

We next tested indicator values of 1 yuan $/ \mathrm{km}$ distance unit price and 0.4 yuan/min duration unit price with vehicle travel speeds from 15 to 40 at a step-wise increase of 1 to calculate optimal transfer passenger volume and $X$ expected profit (Figure 8 ). The transfer passenger volume and X's expected profit both increase as travel speed increases. It is reasonable that more passengers are inclined to use ride-hailing vehicles to save time but less so if ground traffic is congested. X's expected profit reaches its maximum when vehicle speed is $32 \mathrm{~km} / \mathrm{h}$, and slightly declines as speed accelerates. It is reasonable that better transport and pricing conditions inspire more vehicles to expend effort in URT passenger recovery assistance.

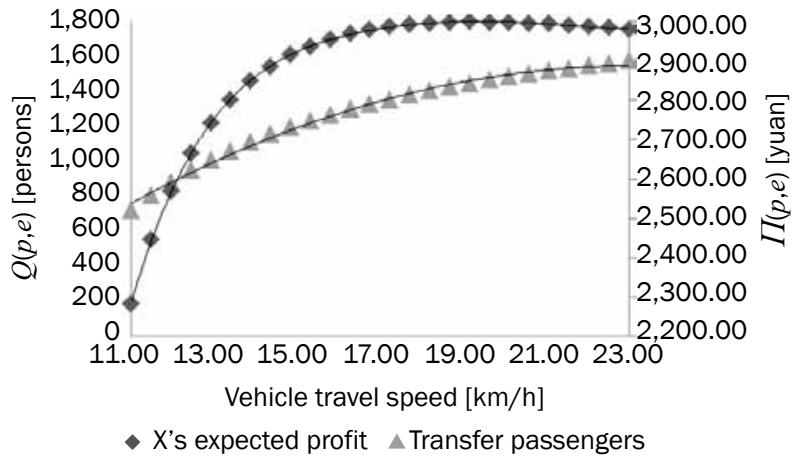

Figure $8-Q(p, e)$ and $\Pi_{r}(p, e)$ changes with different vehicle travel speed

\section{CONCLUSION}

In this study, we explored URT decision-making in providing disruption recovery services for stranded passengers evacuation in collaborating with ride-hailing companies (company " $X$ "). Extant research on this subject has centred on bus-bridging and feeder services - we propose instead an effective collaboration between URT and a ride-hailing company $X$ for stranded passengers evacuation and destination-based services. We established a recovery service supply chain model encompassing ride-hailing vehicles, $\mathrm{X}$, and stranded passengers, then built an effort-based revenue-sharing contract for the coordinated chain in which X's pricing strategy can be adjusted as necessary. We also explored the URT's recovery compensation decision-making process based on a Stackelberg game model wherein the profit functions of the participants' decisions are explicitly assessed and an incentive coefficient parameter for the URT decision and solver is utilized.

This study was not without limitations. For instance, the impact of various aspects of the disruption (e.g., incident areas and time brackets) were neglected. More sophisticated models are necessary to fully capture the characteristics of disruption recovery 
planning. Our delay model could also be further improved - the parameters yet need to be calibrated by more operation data. Using another simulation model as a comparison could more directly reveal the stranded passengers accumulation effects. Additionally, a more balanced analysis may be conducted by applying the method to a larger set of alternative solutions in parallel (e.g. combining shuttle buses and trams in addition to ride-hailing vehicles as recovery service providers). In the future, we plan to consider these factors to further improve upon the methods proposed here.

作者：杨智杰，陈小龙

城市轨道交通中断恢复服务补贴决策

摘要:

共享出行是城市轨道交通 (URT) 中断早期阶段进行 疏散滞留乘客和补充公交接驳的一个有吸引力的选择。本 文提出了一个由共享车辆、共享出行平台和滞留乘客组成 的服务供应链，其中城市轨道交通和共享出行平台共同提 供紧急疏散服务; 紧急疏散服务供应链可以在基于努力的 收益共享契约下实现协调; 建立城市轨道交通与共享出行 平台之间以城市轨道交通为主导的Stackelberg博亦模型, 对城市轨道交通的补贴决策进行优化; 数值分析揭示了影 响上述决策的关键因素。本文的主要贡献有两个方面：一 是提供了城市轨道交通运营公司与共享出行平台之间合 作的新设想, 提出了共享出行平台的定价策略; 二是通过 Stackelberg博弯模型求解城市轨道交通补贴决策过程, 同 时给出了供城市轨道交通决策的激励系数。

\section{关键词：}

城市轨道交通, 恢复服务, 基于努力分担的收益共享契 约, 补贴决策

\section{REFERENCES}

[1] Jespersen-Groth J, Potthoff D, Clausen J, Huisman D, Kroon L, Maróti G, et al. Disruption Management in Passenger Railway Transportation. Berlin Heidelberg: Springer; 2009. p. 399-421.

[2] Pender B, Currie G, Delbosc A, Shiwakoti N. Disruption Recovery in Passenger Railways: International Survey.
Transportation Research Record Journal of the Transportation Research Board. 2013;2353(2353): 22-32.

[3] Kepaptsoglou K, Karlaftis MG. The bus bridging problem in metro operations: conceptual framework, models and algorithms. Public Transport. 2009;1(4): 275-97.

[4] Pender B, Currie G, Delbosc A, Wang Y. Proactive Recovery from Rail Disruptions Through Provision of Track Crossovers and Bus Bridging. Transportation Research Record Journal of the Transportation Research Board. 2012; 2275(-1): 68-76.

[5] Pender B, Currie G, Delbosc A, Shiwakoti N. Improving bus bridging responses via satellite bus reserve locations. J Transp Geogr. 2014;34(34): 202-10.

[6] Westerlund Y, Cazemier O. The use of taxis for special and integrated public transport in Sweden and the Netherlands; 2007.

[7] Darmanin T, Lim C, Gan HS. Public Railway Disruption Recovery Planning: A New Recovery Strategy for Metro Train Melbourne; 2010.

[8] Schuitema G, Steg L, Rothengatter JA. The acceptability, personal outcome expectations, and expected effects of transport pricing policies. J Environ Psychol. 2010;30(4): 587-93.

[9] Zeng AZ, Durach CF, Fang Y. Collaboration decisions on disruption recovery service in urban public tram systems. Transportation Research Part E: Logistics \& Transportation Review. 2012;48(3): 578-90.

[10] Mokhlesian M, Zegordi SH. Application of multidivisional bi-level programming to coordinate pricing and inventory decisions in a multiproduct competitive supply chain. Int J Adv Manuf Tech. 2014;71(9-12): 1975-89.

[11] Yang ZJ, Chen SY, Chen XL, Gu LP. URT Emergency Facilities Location Problem Model in Consideration of Station Vulnerability; 2017.

[12] Wang K, Li X, Xu G. Evaluation of Socio-economic Losses of Train Delay Due to Subway Accident. Urban Mass Transit. 2014.

[13] Lin T, Shalaby A, Miller E. Transit User Behaviour in Response to Service Disruption: State of Knowledge; 2016.

[14] Cachon GP, Lariviere MA. Supply Chain Coordination with Revenue-Sharing Contracts: Strengths and Limitations. Manage Sci. 2005;51(1): 30-44.

[15] Kicsiny R, Varga Z, Scarelli A. Backward induction algorithm for a class of closed-loop Stackelberg games. Eur J Oper Res. 2014;237(3): 1021-36. 